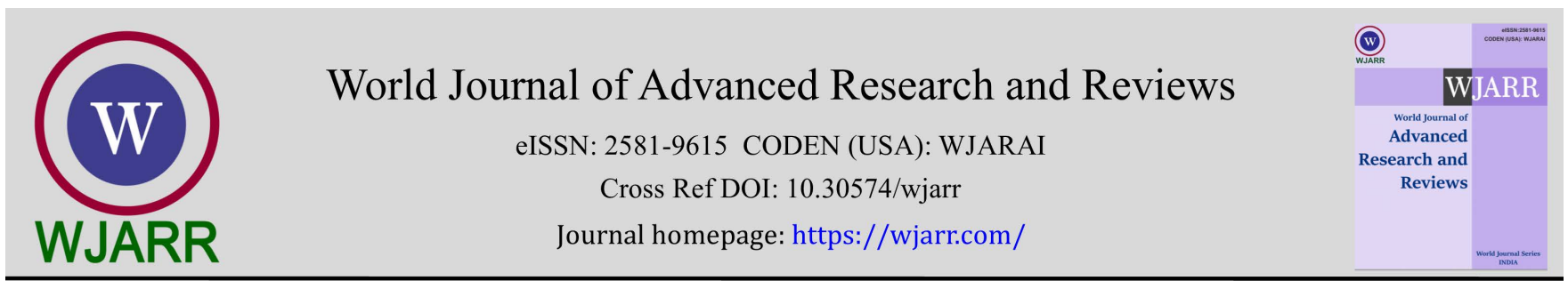

(RESEARCH ARTicle)

\title{
Evaluation of the cytotoxicity of an Ivorian aphrodisiac of natural origin
}

Moussa Gbogbo 1, 2, ${ }^{*}$, Constant Arthur Zébré ${ }^{1}$, Nathalie Connil 3, Mama Koné 2, Elisée Kouassi Kporou 1, Paul Angoué Yapo ${ }^{2}$ and Marc Feuilloley ${ }^{3}$

${ }^{1}$ Jean Lorougnon GUEDE University, BP 150 Daloa, Côte d'Ivoire.

2 Nangui Abrogoua University, 02 BP 801 Abidjan 02 Côte d'Ivoire.

${ }^{3}$ LMSM EA4312 Université de Rouen Normandie, 55 rue Saint Germain, 27000 Evreux, France.

World Journal of Advanced Research and Reviews, 2021, 12(01), 261-267

Publication history: Received on 03 September 2021; revised on 06 October 2021; accepted on 08 October 2021

Article DOI: https://doi.org/10.30574/wjarr.2021.12.1.0509

\begin{abstract}
In Côte d'Ivoire, the market of aphrodisiacs of natural origin has been significantly growing over the last decades. The objective of this study was to evaluate the cytotoxicity of the most employed by Ivorian men, called Aphro.

For that, Caco-2/TC7 enterocytes and Vero ATCC cells kidney epithelial cells grown in DMEM medium were exposed to Aphro at concentrations ranging from 216 to $864 \mu \mathrm{g} / \mathrm{mL}$.

Lactate dehydrogenase (LDH) released upon cell death was assayed after 1, 2 and $24 \mathrm{~h}$ of exposure. In parallel, the effect of Apho was evaluated in differentiated confluent cells by measurements of the trans-epithelial electrical resistance.

A time course and significant dose response related increase of LDH was measured in the culture medium of Caco-2/TC7 and Vero ATCC cells exposed to the aphrodisiac. The trans-epithelial electrical resistance of the Caco-2/TC7 cell monolayers also showed a significant decrease from $1400 \Omega^{*} \mathrm{~cm} 2$ at the onset of the experiment to $450 \Omega^{*} \mathrm{~cm} 2$ after 24 $\mathrm{h}$ of treatment.
\end{abstract}

Cell detachment and structural disorganization were observed in both cell lines. This study reveals the strong cytotoxicity of Aphro extract on both cell lines.

Keywords: Cytotoxicity; Aphrodisiac; Caco-2/TC7; Vero ATCC

\section{Introduction}

Erectile dysfunction is defined as a persistent inability to achieve or maintain an erection that is sufficiently rigid and durable to permit satisfactory sexual intercourse $[1,2,3]$.

Several factors are responsible for erectile dysfunction, including psychological factors $[4,5,6]$ physiological factors (hormonal, hypertension, diabetes) [7, 8, 9]. More than 150 million men are affected worldwide [10]and its prevalence is estimated to more than 300 million people in $2025[11,3]$ with a large increase in developing countries, particularly in Africa, Asia and South America [12]. In Côte d'Ivoire, the prevalence of men affected by erectile dysfunction is unknown. Many drugs have been developed by pharmaceutical industry for the treatment of erectile dysfunctions, but their high cost is a limiting factor $[3,13]$. Thus, in recent years an increasing rush to natural sexual stimulants issued from traditional medicine has been observed. These natural products are sold at almost every street corner and are proposed as syrups, decoctions, herbal tea or powders. One of them (Aphro) remains by far the most popular product

\footnotetext{
* Corresponding author: Moussa Gbogbo

Jean Lorougnon GUEDE University, BP 150 Daloa, Côte d'Ivoire.

Copyright $(2021$ Author(s) retain the copyright of this article. This article is published under the terms of the Creative Commons Attribution Liscense 4.0.
} 
on the market today. However, many testimonials associate the use of this aphrodisiac with the occurrence of immediate side effects: headaches, palpitations, sweating, limbs trembling, instant erection and even priapism crisis [14]. Despite the benefits attributed to this traditional remedy, there is no scientific data available to date on its effect on human health. The aim of this study was to evaluate the cytotoxicity of the Aphro sex stimulant on enterocytes (Caco-2/TC7) and kidney (Vero ATCC) epithelial cells.

\section{Material and methods}

The "Aphro" phytomedicine used for this study was purchased in a sales outlet in the municipality of Abobo (Abidjan, Côte d'Ivoire). Cytotoxicity tests were performed on the following cell lines: a human tumor cell line of intestinal origin isolated from a colonic adenocarcinoma (Caco-2/TC7) and Vero ATCC cells from the kidneys of African green monkey (Certopithecus aethiops). These cell lines were obtained at the Laboratory of Microbiology Signals and Microenvironment of the University of Rouen (France). The culture medium used was Dulbecco's Modified Eagle's Medium (DMEM) with $4.5 \mathrm{~g} / \mathrm{L}$ Glucose and L-Glutamine (Lonza, Belgium) supplemented with: 10 \% (for Vero ATCC) or $15 \%$ (for Caco-2/TC7) of fetal calf serum; penicillin/streptomycin 10,000 U/mL - 10,000 $\mu \mathrm{g} / \mathrm{mL}$ (Biochrom, Germany); Trypsin $(0.05 \%) ; 0.53 \mathrm{mM}$ EDTA and sodium bicarbonate. For the evaluation of cytotoxicity, the non-radioactive Cytotox 96 kit was use. Trans-epithelial electrical resistance was measured in 24-well plates using a Millicell-ERS device (Millipore, Bedford, U.S.A). Cell observations were carried out using a Zeiss Axiovert S100 microscope (Artisan Technology, Canada) equipped with a Nikon DXM 1200F camera.

\subsection{Freeze-drying and preparation of concentrations}

A volume of $1500 \mathrm{~mL}$ of Aphro was filtered and freeze-dried. The freeze-dried material was stored at $4^{\circ} \mathrm{C}$ until use. For all tests, solutions with increasing concentrations of lyophilized Aphro were prepared by dissolving extemporaneously 216,432 or $864 \mu \mathrm{g} / \mathrm{mL}$ of the extract in cell culture medium.

\subsection{Cells culture}

To evaluate the cytotoxicity of the "Aphro" product, Caco-2/TC7 and Vero ATCC cells were cultured in flasks containing DMEM supplemented with $15 \%$ fetal calf serum for Caco-2/TC7 and $10 \%$ for Vero, to which 2 mM L-glutamine, 100 $\mathrm{U} / \mathrm{ml}$ penicillin and streptomycin and $1 \%$ non-essential amino acids were added.

For experimental tests, the cells were seeded at a mean density of $10^{5}$ cells $/ \mathrm{cm}^{2}$ in 24 wells culture plates. The cells were incubated at $37^{\circ} \mathrm{C}$ in $5 \% \mathrm{CO} 2$ atmosphere and the medium was changed daily. Caco-2/TC7 and Vero ATCC cells grown in 24-wells culture plates were incubated until confluence $[15,16]$.

\subsection{Cytotoxicity - lactate dehydrogenase (LDH) test}

Cytotoxicity was determined using an enzyme assay (Cytotox 96 Promega, France) which measures the release of lactate dehydrogenase (LDH), a stable cytoplasmic enzyme, in the medium when the membrane of eukaryotic cells, presently Caco-2/TC7 and Vero ATCC cells, loose integrity during the dying process. LDH is present in many types of eukaryotic cells and its release is considered as an indicator of necrosis. When Caco-2/TC7 and Vero ATCC cells are at confluence, the initial culture medium is replaced by DMEM comprising 216, 432 or $864 \mu \mathrm{g} / \mathrm{mL}$ of lyophilized Aphro. Cells are incubated in drug supplemented medium and aliquots of the culture supernatant are collected at 1, 2 and $24 \mathrm{~h}$ interval, for measurement of LDH release. Two control experiments were carried out for calculation of percentage of cytotoxicity. Caco-2/TC7 and Vero ATCC cells were exposed to Triton X100 (0.9\%) and then used as a positive control for total LDH release $(100 \%$ lysis $)$ as specified by the manufacturer's recommendations. The baseline level ( $0 \%$ LDH release) was determined with untreated culture medium [17].

\subsection{Measurement of the trans-epithelial electrical resistance of the Caco 2/TC7}

Caco-2/TC7 cells were detached from the flasks by trypsin treatment, then $200 \mu \mathrm{L}$ of cell suspensions (106 cells/ml) were seeded in Millipore inserts of $3 \mu \mathrm{m}$ porosity (Millipore Corp, Bedford, USA) of Complete DMEM (800 $\mu \mathrm{L})$ was added in the basal part of the insert. After 15 days of culture $\left(37^{\circ} \mathrm{C}, 5 \% \mathrm{CO} 2\right)$, the epithelial cells start to organize as a monolayer. The culture medium in the insert is removed and replaced with DMEM medium containing 216,432 or 864 $\mu \mathrm{g} / \mathrm{mL}$ of lyophilized Aphro. The integrity of the junctions was assessed by measuring the trans-epithelial resistance using a Millicell-ERS Volt-Ohm meter (Millipore, Bedford, U.S.A.) [18]. 


\subsection{Cells observation}

The cytological effects of the different concentrations of the extracts were assessed at $1 \mathrm{~h}, 2 \mathrm{~h}$ and $24 \mathrm{~h}$ on Caco-2/TC7 and Vero ATCC cells using a Zeiss Axiovert S100 microscope (Artisan Technology, Canada) equipped with a Nikon DXM $1200 \mathrm{~F}$ camera.

\subsection{Statistical analysis}

The statistical analysis was performed using the XLSTAT 2017.1 software. All experiments were repeated three times. The effect of the different concentrations of the extract was compared to that of control cells grown in DMEM and DMEM medium obtained from control cells submitted to total lysis by exposure to Triton X10 by using the following formula [19]:

$\%$ cytotoxicity $=[($ Experimental LDH release (OD490) - Control medium LDH release (OD490)) / (Maximum LDH release (OD490) - Control medium LDH release (OD490)) x 100

where OD 490 is the optical density at $490 \mathrm{~nm}$.

The effects of different concentrations of Aphro were compared using an ANOVA test followed by Dunnet's post hoc tests to determine the statistical difference.

The statistical meanings between untreated control cells and treated cells are represented in the graphs as $\mathrm{p}<0.05\left(^{*}\right)$, $\left.\mathrm{p}<0.01{ }^{* *}\right)$ and $\mathrm{p}<0.001\left(^{* * *}\right)$.

\section{Results}

\subsection{Cytotoxicity: Lactate Dehydrogenase (LDH) assay on Caco 2/TC7 cells}

The evaluation of the cytotoxicity of the phytomedicine Aphro on Caco-2/TC7 and Vero cells was realized at different concentrations and at 1, 2 and 24 h intervals by measuring LDH release. After $1 \mathrm{~h}$ of exposure to Aphro, no significant difference of cytotoxicity (\% LDH release) was observed ( $\mathrm{P}>0.05$ ) using Caco-2/TC7 cultures (Figure 1). A significant increase of LDH release was observed with 216 and $863 \mu \mathrm{g} / \mathrm{mL}$ of lyophilized Aphro after $2 \mathrm{~h}$ of exposure (P $<0.05$ and $\mathrm{P}<0.01$ ). The increase observed using Aphro $432 \mu \mathrm{g} / \mathrm{mL}$ was not statistically significant in comparison to the control (Fig. 1).

After 24h incubation, exposure of Caco-2/TC7 cells to Aphro was leading to an important cell lysis $(\mathrm{P}<0.01$ and $\mathrm{P}<$ 0.001 ) in the treated compared to cells grown in the absence of Aphro (Figure 1).

\subsection{Cytotoxicity: Lactate Dehydrogenase (LDH) assay on Vero ATCC cells}

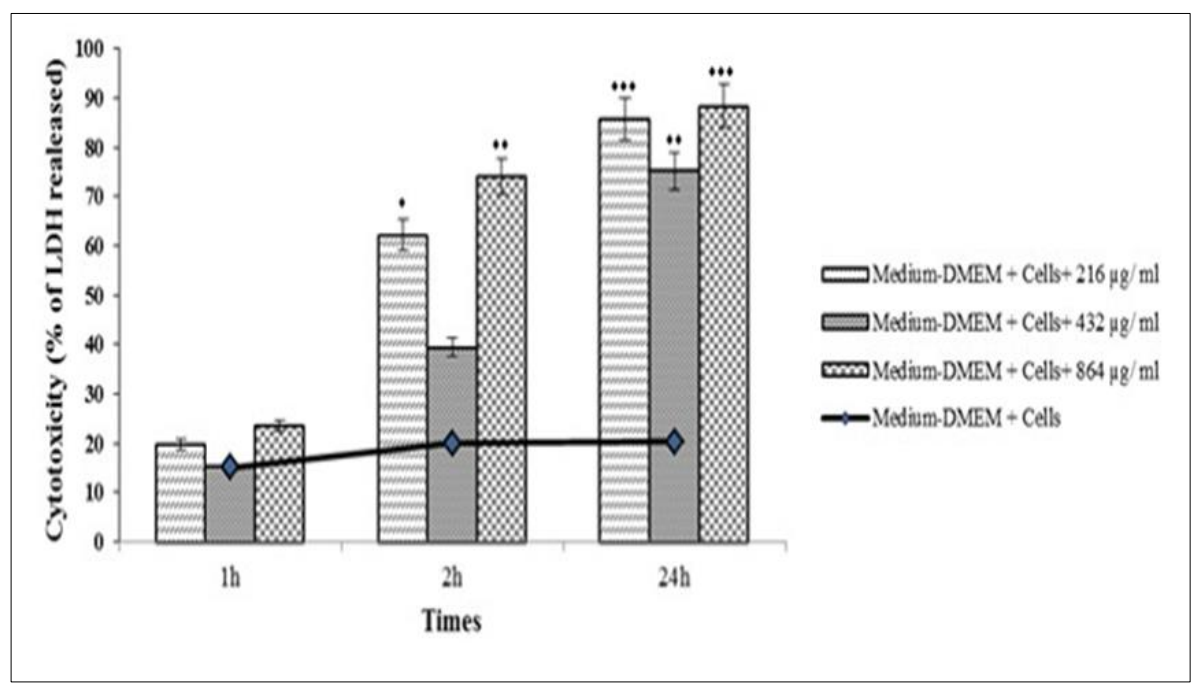

Figure 1 Cytotoxicity of Aphro on Caco 2/TC7 cells at times $1 \mathrm{~h}, 2 \mathrm{~h}$ and $24 \mathrm{~h}$. $*=\mathrm{p}<0.05{ }^{* *}=\mathrm{p}<0.01\left(^{*},{ }^{* *}:{ }^{* *}:\right.$ indicates statistically significant increases) 
When the same experiment was realized using Vero kidney cells, after $1 \mathrm{~h}$ incubation with Aphro, and at all tested concentrations, a very significant increase of LDH was already observed in the culture medium of the cells treated with the phytomedicine ( $<0.001)$ (Figure 2). This effect slightly diminished when Vero ATCC cells were exposed to the phytomedicine for 2 or $24 \mathrm{~h}$, but was still significant $(\mathrm{P}<0.01)$ compared to the control (Figure 2).

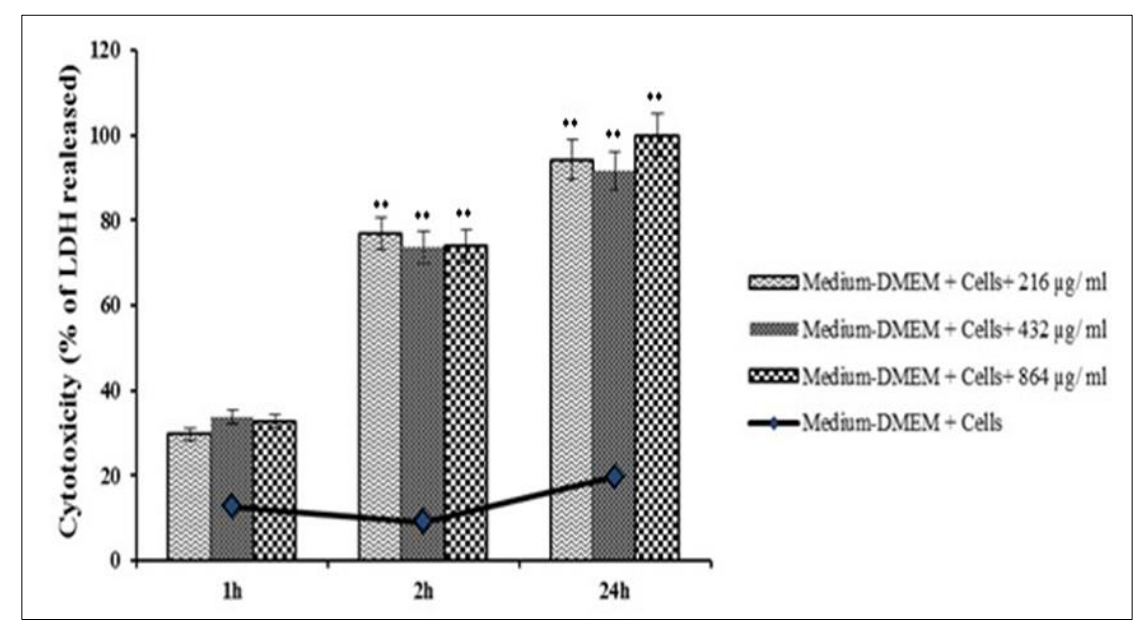

Figure 2 Cytotoxicity of Aphro on ATCC Vero cells at times $1 \mathrm{~h}, 2 \mathrm{~h}$ and $24 \mathrm{~h}$ ${ }^{*}=\mathrm{p}<0.05 ;{ }^{* *}=\mathrm{p}<0.01\left({ }^{*},{ }^{* *}\right.$ : indicates statistically significant increases)

\subsection{Measurement of the trans-epithelial electrical resistance of the Caco 2/TC7}

Evaluation of the trans-epithelial electrical resistance of Caco-2/TC7 cell monolayer was carried out 10 min after removal of the DMEM medium and addition of the extracts incorporated into the complete medium. No significant difference in trans-epithelial resistance was observed in the culture media as a whole compared to the control (Figure 3). After $1 \mathrm{~h}$ of contact, a significant drop in trans-epithelial electrical resistance was observed in the culture medium containing the phytodrug at the highest concentration $(864 \mu \mathrm{g} / \mathrm{ml})(\mathrm{P}<0.05)$. No difference was measured at other doses. After 2 and $24 \mathrm{~h}$ of exposure, a very significant drop in trans-epithelial resistance was observed for all cells treated with the phytodrug extract at the three tested doses of 216,432 and $864 \mu \mathrm{g} / \mathrm{mL}(\mathrm{P}<0.05 ; \mathrm{P}<0.01$ and $\mathrm{P}<0.001$, respectively) (Figure 3).

\subsection{Cells observation}

Concerning the morphology of the cells treated with Aphro, structural disorganization was observed in both cell lines (Figures 4c, 4d, 4f, 4g and 4h). The cells in the treated batches showed a shrinking in size (plasmolysis) and a clear loss on intercellular contacts (Figures 4c, 4d, $4 \mathrm{~g}$ and $4 \mathrm{~h}$ ).

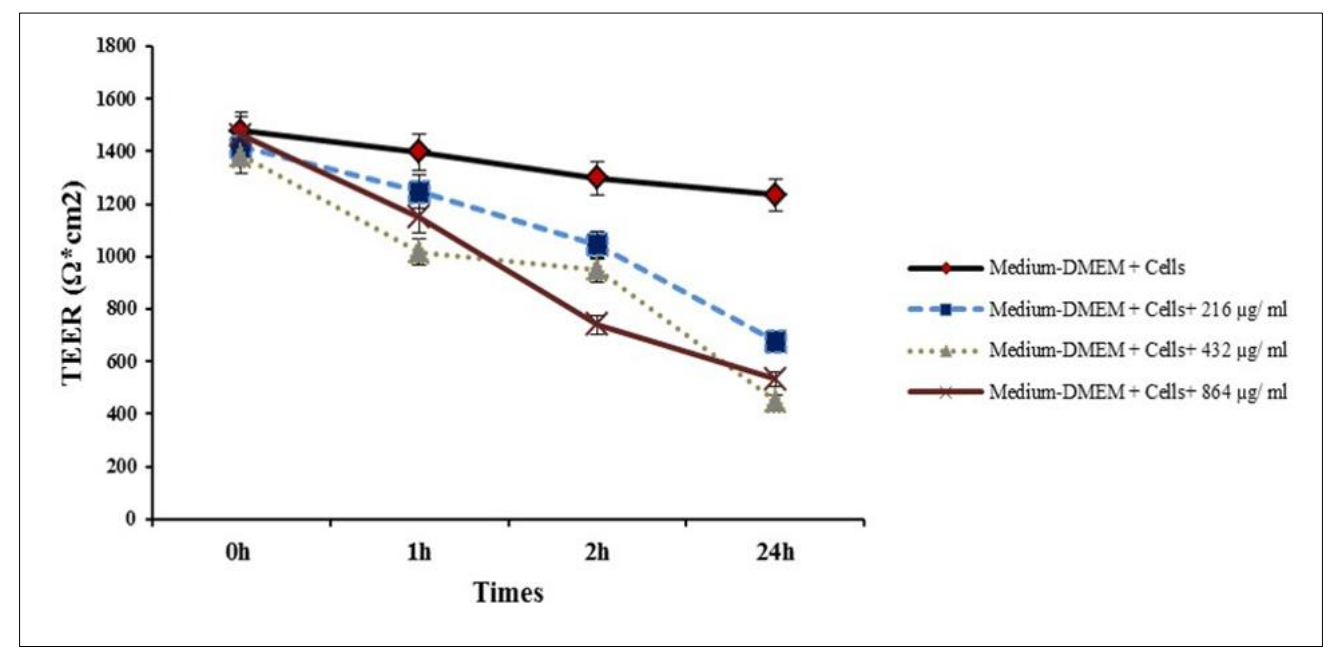

Figure 3 Effects of Aphro on the trans-epithelial electrical resistance (TEER) of CaCo2/TC7 cells over a 24h period 1h, $2 \mathrm{~h}$ and $24 \mathrm{~h} .{ }^{*}=\mathrm{p}<0.05 ;^{* *}=\mathrm{p}<0.01\left({ }^{*}, * *\right.$ indicates statistically significant increases) 


\section{Discussion}

The cytotoxic effect of the phytodrug Aphro on Caco-2/TC7 and Vero ATCC cells was evaluated by quantifying the LDH release in culture medium. The LDH test provides a simple means for measuring plasma membrane damage, based on the release of lactate dehydrogenase, a cytoplasmic enzyme present in many cells [20]. The results indicate a significant increase in enzyme release in the batches treated with the phytomedicinal product compared to the controls. These results demonstrate the cytotoxicity of Aphro on Caco-2/TC7 and Vero ATCC cells.

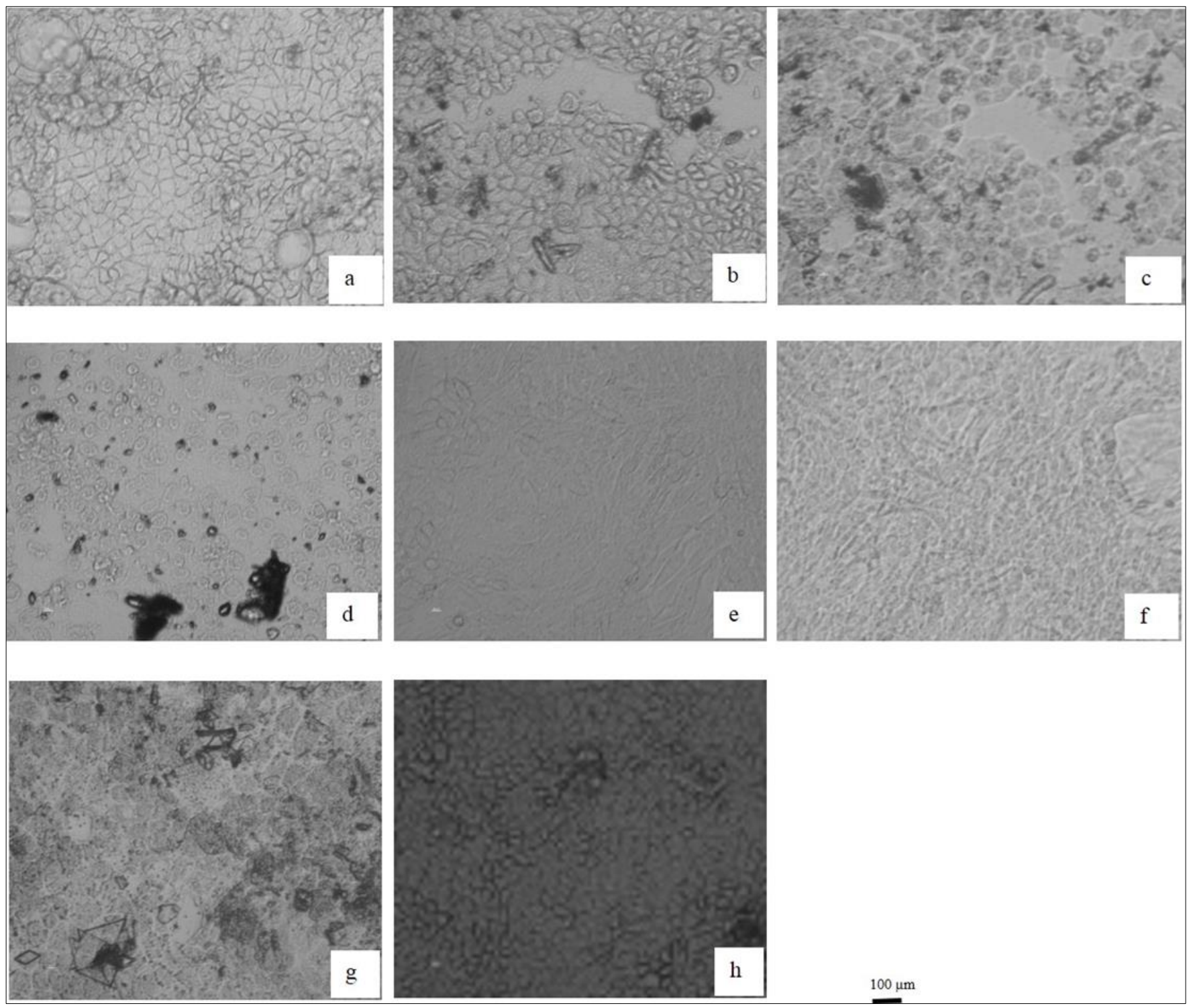

Figure 4 Observations characteristics of Caco-2/TC7 and Vero ATCC cells treated with Aphro after 24h a: Microphotograph of confluent Caco-2/TC7 cells in the control culture medium.

b: Microphotograph of Caco-2/TC7 cells treated with Aphro at the concentration of $216 \mu \mathrm{g} / \mathrm{ml}$.

c: Microphotograph of Caco-2/TC7 cells treated with Aphro at concentration $=432 \mu \mathrm{g} / \mathrm{ml}$.

$\mathrm{d}$ : Microphotograph of Caco-2/TC7 cells treated with Aphro at concentration of $864 \mu \mathrm{g} / \mathrm{ml}$.

e: Microphotograph of Vero ATCC cells present in the control culture medium.

$\mathrm{f}$ : Microphotograph of Vero ATCC cells in the culture medium treated with Aphro at concentration of $216 \mu \mathrm{g} / \mathrm{ml}$. g: Microphotograph of Vero ATCC cells in the culture medium treated with Aphro at concentration of $432 \mu \mathrm{g} / \mathrm{ml}$. h: Microphotograph of Vero ATCC cells in the culture medium treated with Aphro at concentration of $864 \mu \mathrm{g} / \mathrm{ml}$.

Our results are coherent with those obtained by George et al. [21] who indicated a concentration-dependent increase in LDH release in Caco-2/TC7 cells treated with acetone extract from the roots of Rubus fairholmianus Gard, a phytodrug. 
Our results also show a strong cytotoxicity of Aphro on Vero ATCC cells. This toxicity appears within the first hours and more rapidly than in Caco-2/TC7 and therefore suggest a higher sensitivity of Vero kidney cells to Aphro. This difference in sensitivity of the two cell lines was not elucidated during our study but we can suggest that as Vero cells originate from an elimination organ (kidney) they should be more sensitive to a toxic compound such as Aphro.

The barrier properties of intestinal and kidney epithelial models formed by Caco-2/TC7 and Vero ATCC cells grown over 10 days were evaluated by measuring the trans-epithelial electrical resistance. A decrease in the trans-epithelial electrical resistance of Caco-2/TC7 cell monolayers is considered as an indication of rupture of tight junctions between epithelial cells, indicating an increase in the paracellular permeability of the epithelial cell layer [22].

During our study, a significant decrease in trans-epithelial electrical resistance of the Caco-2/TC7 monolayers was observed in the batches treated with the phytodrug drug Aphro at all concentrations. These results suggest a loss of intercellular contacts through tight junctions. However we cannot rule out a potential effect of Aphro on plasma membrane permeability or integrity. Aphro seems therefore to be cytotoxic on Caco-2/TC7 through different mechanisms. Our results are consistent with those obtained by Wonfor et al. [23] who showed a significant reduction $(\mathrm{P}<0.05)$ in the value of the trans-epithelial electrical resistance of Caco-2/TC7 cells when treated with extracts of Maytenus ilicifolia Mart. e.g. Reiss, (Celastraceae), a phytodrug at concentrations ranging from 12.5 to $200 \mu \mathrm{g} / \mathrm{mL}$.

Brucker et al. [24] demonstrated that the increase in permeability of HT-29 colonic epithelial cells monolayers was due to an embrittlement of their plasma membrane. This embrittlement leads to a decrease in trans-epithelial resistance and is correlated with the decrease in tight junction proteins such as claudines and occludines. Our results would therefore argue in favour of the toxic nature of Aphro, which could produce harmful effects on the junctions of Caco2/TC7 cells, causing high membrane permeability which results in a significant decrease in trans-epithelial electrical resistance.

Concerning the cell morphology, we observed different architectures of the two cell lines treated with the phytomedicine compared to the control batches after $24 \mathrm{~h}$ of exposure. The Caco-2/TC7 and Vero ATCC cells treated during our study had the appearance of being isolated from each other whereas in control studies they were compacted and confluent. These observations corroborate well the results obtained during the evaluation of cytotoxicity using the LDH test and trans-epithelial electrical resistance measurement. Our observations corroborate the results of Monga et al. [25] Indeed, these authors noted that test batches cells exhibited the typical morphology of cells undergoing apoptosis, such as detachment from the culture plate, cytoplasmic condensation, cell shrinkage, condensation and aggregation of nuclear chromatin, and loss of contact with neighboring cells.

\section{Conclusion}

This work shows that at concentrations of 216, 432 and $864 \mu \mathrm{g} / \mathrm{mL}$, the phytomedicinal drug Aphro induces cytotoxicity on human tumor cells of intestinal origin isolated from the colonic adenocarcinoma (Caco-2/TC7) and kidney Vero ATCC cells of African green monkey (Certopithecus aethiops.) origins . This cytotoxic appears rapid and massive leading to disorganization of the plasma membrane and epithelium integrity. Taken together, these data reinforce the concerns on the safety of Aphro and indicate that it should be employed with the greatest caution, if its use cannot be banned.

\section{Compliance with ethical standards}

\section{Acknowledgments}

The authors wish to thank the Laboratory of Microbiology Signals and Microenvironment (University of Rouen, France) which provided all the cell lines and the technical material for the performance of this study.

\section{Disclosure of conflict of interest}

The authors declare no conflict of interest.

\section{References}

[1] National Institute of Health Consensus Conference (NIHCC). Impotence: consensus development Panel on Impotence. JAMA. 1993; 270: 83-90. 
[2] Chena L, Shib GR, Huangc DD, et al. Male sexual dysfunction: A review of literature on its pathological mechanisms, potential risk factors, and herbal drug intervention. Biomed Pharmacother. 2019; 112: 1-13.

[3] Masuku NP, Unuofin JO, Lebelo SL. Promising role of medicinal plants in the regulation and management of male erectile dysfunction. Biomed Pharmacother. 2020; 130: 1-17.

[4] Foreman MM, Doherty PC. Experimental approaches for the development of pharmacological therapies for erectile dysfunction. Riley AJ Peet Ed, Sexual pharmacology. Oxford: Clarendon Press, 1993; 87-113.

[5] Morano S, Gatti A, Mandosi E, et al. Circulating monocyte oxidative activity is increased inpatients with type2 diabetes and erectile dysfunction. J Urol. 2007; 177: 655- 59.

[6] Patel JP, Lee EH, Mena-Hurtado CI, Walker CN. Evaluation and management of erectile dysfunction in the hypertensive patient. Curr Cardiol Rep. 2017; 19: 89.

[7] Meston CM, Frohlich PF. The neurobiology of sexual function. Arch Gen Psychiatry 2000; 57: $1012-30$.

[8] Kuhn CM, Walker QD, Kaplan KA, Li ST. Sex, steroids, and stimulant sensitivity. Ann N Y Acad Sci 2001; 937: 188201.

[9] Phéa V, Rouprêt M, Ferhi B, et al. Étiologie et prise en charge de la dysfonction érectile chez le patient diabétique. Prog Urol. 2009; 19: 364-71.

[10] Bondil P. La dysfonction érectile. Pathologie Sciences. Éditions John Libbey Eurotext, Paris 2003; $218: 55$.

[11] McKinlay JB. The worldwide prevalence and epidemiology of erectile dysfunction. Int J Imp Res. 2000; 12 : 6-11.

[12] Ayta I, Mckinlay JB, Krane RJ. The likely worldwide increase in erectile dysfunction between 1995 and 2005 and some possible policy consequences. BJU Int. 1999; 84: 50-56.

[13] Nimrouzi M, Jaladat AM, Zarshenas MM. A panoramic view of medicinal plants traditionally applied for impotence and erectile dysfunction in Persian medicine. J Tradit Complement Med. 2018; 1-6.

[14] Doingbuzz. https://doingbuzz.com/apres-avoir-consomme-un-aphrodisiaque-son-erection-ne-descend-plus/ Visited on $03 / 30 / 2020$ at $11: 12$ p.m.

[15] Madi A, Svinareff P, Orange N, et al. Pseudomonas fluorescens alters epithelial permeability and translocates across Caco-2/TC7 intestinal cells. Gut Pathogens. 2010; 2: 16.

[16] Shin SH, Bae MJ, Jung YS, et al. Enhancing effect of trachelogenin from Trachelospermi caulis extract on intestinal barrier function. Biol Pharm Bull. 2015; 38: 1707-13.

[17] Zommiti M, Cambronel M, Maillot 0, et al. Evaluation of probiotic properties and safety of Enterococcus faecium isolated from artisanal tunisian meat "Dried Ossban". Front Microbiol. 2018; 9: 1-12.

[18] Hsieh SL, Hsieh S, Kuo YH, et al. Effects of Panax notoginseng on the Metastasis of Human Colorectal Cancer Cells. The American Journal of Chinese Medicine. 2016; 44: 851- 70.

[19] Chen J, Douglas GC, Twanda L, et al. Effect of bromodichloromethane on chorionic gondadotrophin secretion by human placental trophoblast cultures. Toxicol Sci. 2003; 76: 75-82.

[20] Chou CC, Wu YC, Wang YF, et al. Capsaicin-induced apoptosis in human breast cancer MCF-7 cells throughcaspase-independent pathway. Oncol Rep. 2009; 21: 665-71.

[21] George BPA, Tynga IM, Abrahamse H. In Vitro Antiproliferative effect of the acetone extract of Rubus fairholmianus Gard. Root on Human colorectal cancer cells. BioMed Res Int. 2015; 1-8.

[22] Schipper GM, Olsson S, Hoogstraate JA, et al. Chitosan as absorption enhancers for poorly absorbable drugs 2: mechanism of absorption enhancement. Pharm Res. 1997; 14: 923-929.

[23] Wonfor R, Natoli M, Parveen I, et al. Anti-inflammatory properties of an extract of M.ilicifolia in the human intestinal epithelial Caco-2 cell line. J Ethnopharmacol. 2017; 209: 283- 87.

[24] Bucker R, Troeger H, Kleer J, et al. Arcobacter butzleri induces barrier dysfunction in intestinal HT-29/B6 cells. J Infect Dis. 2009; 200: 756-64.

[25] Monga J, Pandit S, Chauhan CS, Sharma M. Cytotoxicity and apoptosis induction in human breast adenocarcinoma MCF-7 cells by (+)-cyanidan-3-ol. Exp Toxicol Pathol. 2013; 65: 1091-1100. 